\title{
The Double Burden of Infectious Diseases and Diabetes- A Bidirectional Relationship
}

\author{
Eugene Sobngwi, MD, PhD ${ }^{1}$ and Jean Claude Mbanya, MD, PhD, FRCP (UK)²
}

\begin{abstract}
1. Associate Professor, National Obesity Centre, Yaoundé Central Hospital, Yaoundé, Cameroon; 2. Professor of Medicine and Endocrinology, Department of Internal Medicine and Specialties, Faculty of Medicine and Biomedical Sciences, University of Yaoundé 1 and Laboratory of Molecular Medicine and Metabolism,
\end{abstract}

The Biotechnology Centre, University of Yaoundé 1, Cameroon

\begin{abstract}
There is growing evidence for an etiological interaction between infectious diseases and diabetes, as well as for bidirectional influence of clinical presentation, spread, and outcomes. Some HIV treatments increase diabetes risk, and some infectious diseases may determine unique phenotypes of diabetes. Individuals who have type 2 diabetes have increased risk for tuberculosis and viral hepatitis and have poorer treatment outcomes. Joint noncommunicable diseases (NCDS) and infectious diseases clinics are the ideal method of tackling the double burden of these diseases in developing countries.
\end{abstract}

\section{Keywords}

Diabetes, infectious diseases, non-communicable diseases, developing countries

Disclosure: Eugene Sobngwi, MD, PhD, and Jean Claude Mbanya, MD, PhD, FRCP (UK), have no conflicts of interest to declare. No funding was received for the publication of this article.

Open Access: This article is published under the Creative Commons Attribution Noncommercial License, which permits any noncommercial use, distribution, adaptation, and reproduction provided the original author(s) and source are given appropriate credit.

Received: April 7, 2015 Accepted: April 14, 2015 Citation: US Endocrinology, 2015;11(1):24-5 DOI: http://doi.org/10.17925/USE.2015.11.1.24

Correspondence: Jean Claude Mbanya, MD, PhD, FRCP (UK), Professor of Medicine and Endocrinology, Faculty of Medicine and Biomedical Sciences, University of Yaoundé I, BP 8046, Yaoundé, Cameroon. E: jcmbanya@yahoo.co.uk

In 1971, Omran described the concept of epidemiologic transition to improve the understanding of patterns of disease in opposition of single disease epidemiology across the world and to provide better forecast and societal response to disease patterns. ${ }^{1}$ Although three main types of transition were described, including the classic transition experienced by most developed countries, the accelerated transition experienced by countries such as Japan and Mauritius, and the delayed transition that accommodates the so-called double burden of disease, it is now widely accepted that many countries face different stages of transition as a result of inequalities. The pattern of disease thus varies across countries, but also across populations or settings within the same country, defining the polarized model of health transition. Emerging and re-emerging pandemics coexist with the burgeoning noncommunicable disease epidemic.

The relation between infectious diseases and the most common noncommunicable disease is not yet fully understood. But there is growing evidence for an etiological interaction, as well as for interactions influencing clinical presentation, spread, and outcomes of these diseases.

Chronic noncommunicable diseases (NCDS), such as diabetes, cardiovascular diseases (CVD), and cancers, are emerging as leading causes of mortality and morbidity in sub-Saharan Africa (SSA), where an estimated 22 million people lived having diabetes in $2014 .^{2}$ In the near future, SSA is expected to undergo the largest proportional increase in the burden of diabetes, with an estimated 41.5 million Africans expected to be living with the disease by $2035 .{ }^{3}$ Similarly, it is expected that in 2015, an estimated 1.2 million deaths will be attributable to CVD in this region. ${ }^{4}$ Moreover, this figure is expected to double by $2030 .{ }^{4}$ Substantial progress has been made in Africa in reducing the burden of many types of infectious diseases, but the big killers-tuberculosis (TB), malaria, HIV, hepatitis $B$, and hepatitis $\mathrm{C}$-remain endemic across SSA.

The relationship between infectious and noninfectious diseases is thought to be bidirectional. For instance, individuals who have type 2 diabetes (T2D) have a threefold-increased risk for TB, as well as poorer treatment outcomes, ${ }^{5} \mathrm{HIV}$ antiretroviral treatment (ART) has been linked to the development of the metabolic syndrome, ${ }^{,, 7}$ and T2D affects clinical outcomes in patients who have hepatitis., ${ }^{8,9}$ The convergence of these conditions presents new challenges and opportunities to enact responsive changes in research and disease management. ${ }^{10}$

The increasing survival among people infected by HIV in developing countries - a result of better access to ART-decreased mortality, and increased life expectancy are paralleled by a growing burden of CVD and diabetes mellitus. ${ }^{11}$ There is evidence to suggest that NCDs will grow even more quickly among people who have HIV, whether as the result of 
the natural history of the infection itself or as a result of related coinfections and treatments. For instance, HIV infection is associated with increased risk for insulin resistance (IR), and some ART treatment regimens have been found to be associated with metabolic derangements, in particular the occurrence of T2D. 12,13 Likewise, TB and viral hepatitis coinfection are highly common in people having HIV infection and are independently associated with increased risk for T2D. ${ }^{14,15}$ However, the contribution of HIV infection, ART, and coinfections to the predicted doubling of diabetes prevalence in Africa over the next 20 years is insufficiently addressed. IR is the central mechanism underlying HIV lipodystrophy, as well as a key mechanism in the development of impaired glucose tolerance and diabetes. Active TB and viral hepatitis $\mathrm{C}$ also increase IR. ${ }^{14,15}$

Infectious diseases may determine unique phenotypes of diabetes in SSA. In addition to changing epidemiology, sub-Saharan Africans have unique clinical phenotypes of diabetes. Up to $25 \%$ may have presentations of uncertain classification and etiology and thus uncertain treatment strategies. ${ }^{11}$ The most frequent atypical presentation is ketosis-prone atypical diabetes. ${ }^{11}$ Classic risk factors cannot solely explain the differences in epidemiology and phenotypes of diabetes (see Figure 1). Recent investigations suggest interaction with infectious diseases, especially some viral infections, such as human herpes viruses. ${ }^{16}$ In addition, host genetic factors modulating both infectious and noninfectious disease outcomes are expected to differ in. However, large-scale multicountry evidence is lacking with which to appraise the role of infectious diseases on the epidemiology, clinical presentation, and outcomes of diabetes.

Prevention is the cornerstone of any pragmatic diabetes program, and there is strong evidence of the effectiveness of lifestyle and pharmacologic approaches at postponing or preventing T2DM occurrence in individuals in the general population who are at high risk. Whether such approaches could prevent HIV-infected individuals, whether with or without active

\section{Figure 1: Hypothesized Influence of Viral Infection on Diabetes Phenotype}

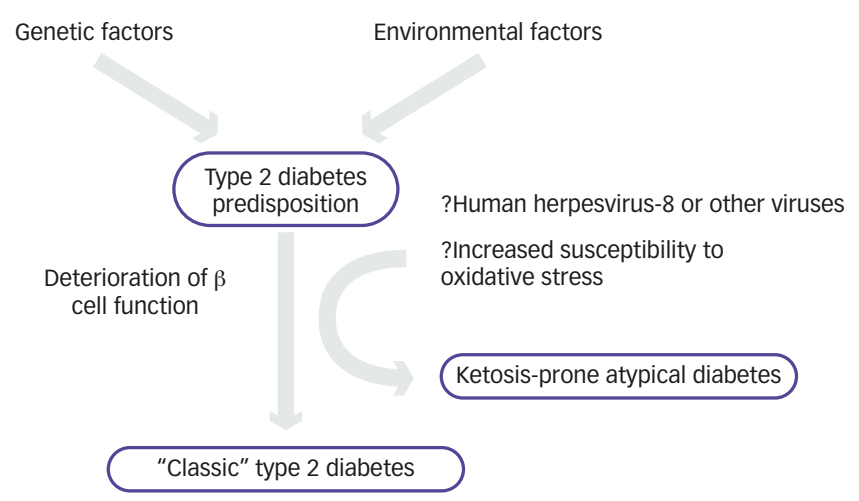

$T B$, from developing diabetes is not known. Limited-scale evidence of feasibility and safety of metformin and exercise intervention exist in HIV-infected people having impaired glucose tolerance, ${ }^{17,18}$ but not to an extent that can be translated into recommendations.

Mechanisms have been put in place by the global community to tackle HIV, TB, and malaria_-but not NCDS—in developing countries, thus creating two parallel healthcare systems operating within these countries and sometimes even in the same hospital: a well-equipped, fully funded, and well-trained healthcare providers system for patients suffering from these infectious disease and an orphaned NCDS system for diabetes and CVDS. Establishing joint clinics for both NCDs and infectious diseases, especially in underserved rural populations, to maximize task shifting of the limited number of health workers and the cost-effective use of equipment purchased through major HIV, TB, and malaria global initiatives is the ideal response to tackling the high burden of diabetes in developing countries.
1. Omran AR, The epidemiologic transition: a theory of the epidemiology of population change, 1971, Bull World Health Organ, 2001;79:161-70

2. International Diabetes Federation, Diabetes Atlas, 6th edition, Brussels, Belgium: International Diabetes Federation, 2014. Available at: www.idf.org/diabetesatlas/5e (accessed April 21, 2015).

3. Peer N, Kengne AP, Motala AA, Mbanya JC, Diabetes in the Africa region: an update, Diabetes Res Clin Pract, 2014;103:197-205.

4. WHO, Projections of mortality and causes of death, 20152030. Available at: www.who.int/healthinfo/global_burden disease/projections/en/ (accessed April 21, 2015).

5. Restrepo BI, Schlesinger LS, Host-pathogen interactions in tuberculosis patients with type 2 diabetes mellitus, Tuberculosis (Edinb), 2013;(Suppl. 93):S10-4.

6. Dillon DG, Gurdasani D, Riha J, et al., African Partnership for Chronic Disease Research (APCDR), Association of HIV and ART with cardiometabolic traits in sub-Saharan Africa: a systematic review and meta-analysis, Int J Epidemiol, 2013:42:1754-71.
7. Hall V, Thomsen RW, Henriksen O, Lohse N, Diabetes in sub-Saharan Africa 1999-2011: epidemiology and public health implications-a systematic review, BMC Public Health, 2011:11:564.

8. Macaluso FS, Maida M, Minissale MG, et al., Metabolic factor and chronic hepatitis C: a complex interplay, Biomed Res Int 2013(2013):564-645

9. Wang C, Wang X, Gong G, et al., Increased risk of hepatocellular carcinoma in patients with diabetes mellitus: a systematic review and meta-analysis of cohort studies, Int I Cancer, 2012:130:1639-48.

10. Remais JV, Zeng G, Li G, et al., Convergence of noncommunicable and infectious diseases in low- and middle-income countries, Int J Epidemiol, 2013;42:221-7.

11. Mbanya JC, Motala AA, Sobngwi E, et al., Diabetes in subSaharan Africa, Lancet, 2010;375(9733):2254-66.

12. Paik IJ, Kotler DP, The prevalence and pathogenesis of diabetes mellitus in treated HIV-infection, Best Pract Res Clin Endocrino Metab, 2011:25:469-78.

13. Levitt NS, Bradshaw D, The impact of HIV/AIDS on Type 2 diabetes prevalence and diabetes healthcare needs in South Africa: projections for 2010, Diabet Med, 2006;23:103-4.

14. White DL, Ratziu V, El-Serag HB, Hepatitis $\mathrm{C}$ infection and risk of diabetes: a systematic review and meta-analysis, $J$ Hepatol 2008:49:831-44.

15. Young F, Critchley JA, Johnstone LK, Unwin NC, A review of co-morbidity between infectious and chronic disease in subSaharan Africa: TB and diabetes mellitus, HIV and metabolic syndrome, and the impact of globalization, Global Health. 2009:5:9.

16. Sobngwi E, Choukem SP, Agbalika F, et al., Ketosis-prone type 2 diabetes mellitus and human herpesvirus 8 infection in subSaharan Africans, JAMA, 2008;299:2770-6.

17. Hadigan C, Corcoran C, Basgoz N, et al., Metformin in the treatment of HIV lipodystrophy syndrome: a randomized controlled trial, JAMA, 2000;284:472-7.

18. Driscoll SD, Meininger GE, Lareau MT, et al., Effects of exercise training and metformin on body composition and cardiovascular indices in HIV-infected patients, AIDS, 2004:18:465-73. 